\title{
Efficacy and Safety of Naftopidil in Patients With Neurogenic Lower Urinary Tract Dysfunction: An 8-Week, Active-Controlled, Stratified-Randomized, Double-Blind, Double-Dummy, Parallel Group, Noninferiority, Multicenter Design
}

\author{
Hyun Hwan Sung ${ }^{1}$, Myung-Soo Choo ${ }^{2}$, Joon Chul Kim ${ }^{3}$, Jang Hwan Kim ${ }^{4}$, Kyu-Sung Lee ${ }^{1,5}$ \\ ${ }^{1}$ Department of Urology, Samsung Medical Center, Sungkyunkwan University School of Medicine, Seoul, Korea \\ ${ }^{2}$ Department of Urology, Asan Medical Center, University of Ulsan College of Medicine, Seoul, Korea \\ ${ }^{3}$ Department of Urology, College of Medicine, The Catholic University of Korea, Seoul, Korea \\ ${ }^{4}$ Department of Urology, Yonsei University College of Medicine, Seoul, Korea \\ ${ }^{5}$ Department of Medical Device Management \& Research, SAIHST, Sungkyunkwan University, Seoul, Korea
}

Purpose: The aim of this study was to evaluate the efficacy and safety of naftopidil compared with tamsulosin in patients with neurogenic lower urinary tract dysfunction (LUTD).

Methods: This study was conducted as an 8-week, active-controlled, stratified-randomized, double-blind, double-dummy, parallel group, noninferiority, and multicenter clinical trial. After 2 weeks of screening, eligible subjects were randomly assigned to receive naftopidil ( $25 \mathrm{mg}$ for 1 week followed by $75 \mathrm{mg}$ for 7 weeks) or tamsulosin ( $0.2 \mathrm{mg}$ for 8 weeks). Primary endpoint was a change of International Prostatic Symptom Score (IPSS) total score after 8 weeks of treatment.

Results: One hundred ninety-four subjects with neurogenic LUTD were included into this trial. There were no differences between the 2 groups in baseline characteristics, including urodynamic study results, subtype of LUTD, pretreatment and concomitant medication, and causes of neurogenic bladder. The medication compliance rate was $94.0 \%$ (naftopidil, $93.6 \%$; tamsulosin, 94.4\%). There was a statistically significant decrease of IPSS total score at 8 weeks versus baseline in both the naftopidil $(-5.64 \pm 0.66)$ and tamsulosin $(-6.53 \pm 0.65)$ groups $(\mathrm{P}<0.0001$ each). The mean difference between both groups was 0.89 (upper limit of $95 \%$ confidential interval, 2.72), which was lower than the noninferiority limit of 3 points. A subgroup analysis of neurologic lesions and sex found no mean difference of IPSS total score in each group. There was also no difference in safety profiles, including treatment emergent adverse events.

Conclusions: Naftopidil was not inferior to tamsulosin as a therapeutic drug for patients with neurogenic LUTD and had a similar safety profile.

Keywords: Neurogenic; Lower urinary tract symptoms; Naftopidil; Urinary bladder

- Research Ethics: The Internal Review Board of each center approved this trial and written informed consent was obtained from all participants before screening. This study was registered in ClinicalTrials.gov (NCT02034604).

- Conflict of Interest: This study was sponsored by Dong-A ST Co., Ltd., Seoul, Korea and Asahi Kasei Pharma Co., Ltd., Tokyo, Japan. No potential conflict of interest relevant to this article was reported.

Corresponding author: Kyu-Sung Lee (iD https://orcid.org/0000-0003-0891-2488 Department of Urology, Samsung Medical Center, Sungkyunkwan University School of Medicine, 81 Irwon-ro, Gangnam-gu, Seoul 06351, Korea E-mail:ksleedr@gmail.com

Submitted: October 29, 2019 / Accepted after revision: February 22, 2020 (i) (2) This is an Open Access article distributed under the terms of the Creative Commons Attribution Non-Commercial License (https://creativecommons.org/licenses/by-nc/4.0/) which permits unrestricted non-commercial use, distribution, and reproduction in any medium, provided the original work is properly cited. 


\section{INTRODUCTION}

Neurogenic lower urinary tract dysfunction (LUTD) is common in patients with various neurological diseases. Alphablockers have been shown to be effective treatments for improving storage symptoms as well as voiding symptoms in neurogenic LUTD [1,2]. Alphala-adrenergic receptors (ARs) predominate in the human prostate; blockade relaxes prostatic smooth muscle and increases urine flow [3], and ald-ARs predominate in human detrusor, spinal cord, and afferent nerves, where blockade decreases LUTD symptoms. Thus, $\alpha 1$-AR act not only directly on the smooth muscle, but also on the spinal cord, ganglion and nerve endings affecting sympathetic and parasympathetic nerves [4]. Alphal-blockers have been shown to reduce urinary tract resistance in patients with neurogenic LUTD and are effective in the treatment of voiding dysfunction, even in female patients [5].

Naftopidil was also reported to be effective on both symptoms and urodynamic variables of patients with neurogenic LUTD in a noncomparative, single-arm study [6]. Naftopidil is reported to have a 3-fold higher affinity for a1D-AR than a1A$\mathrm{AR}$, while tamsulosin and silodosin have much more affinity for a1A-AR than $\alpha 1 D-A R[7,8]$. Naftopidil appears to have similar effects on urological symptom scores and quality of life (QoL) compared to tamsulosin and silodosin in patients with nonneurogenic LUTD, such as benign prostatic hyperplasia [9]. Currently marketed $\alpha$-blockers, including naftopidil, are being prescribed in patients with neurogenic LUTD in several countries. However, the clinical effects of naftopidil on neurogenic LUTD have been rarely reported. Therefore, we evaluated the efficacy and safety of naftopidil in patients with neurogenic LUTD.

\section{MATERIALS AND METHODS}

This study was conducted as an 8-week, active-controlled, stratified-randomized, double-blind, double-dummy, parallel group, noninferiority, and 15-multicenter clinical trial. The internal review board of each center approved this trial and written informed consent was obtained from all participants before screening. This study was registered in ClinicalTrials.gov (NCT02034604). The screening period was up to 2 weeks and the double-blind treatment period was 8 weeks.

This trial consisted of screening (visit 1), random assignment (visit 2), and follow-up at week 4 (visit 3), and week 8 (visit 4). After the screening test, eligible subjects were randomly as- signed to 1 of 2 treatment groups (naftopidil or tamsulosin) by institution and sex at a ratio of 1:1. Subjects received either 25 $\mathrm{mg}$ of naftopidil for 1 week followed by $75 \mathrm{mg}$ of naftopidil for 7 weeks, or $0.2 \mathrm{mg}$ of tamsulosin for 8 weeks. International Prostatic Symptom Score (IPSS), uroflowmetry and postvoid residual (PVR) were conducted at screening visits 1,3 , and 4 . Voiding diary was assessed at visits 2, 3, and 4, and the subject surveys (Benefit, Satisfaction, and Willingness to Continue Questionnaire [BSW-Q] [10], Global Response Assessment for Koreans [GRA-K], and Treatment Satisfaction Questionnaire [TSQ]) were administered at visits 3 and 4 . The GRA measures the overall improvement with therapy. The assessment asks: "As compared to when you started the current study (treatment), how would you rate your overall lower urinary tract symptoms now?". The patient was provided with the following 7 response options: markedly worse, moderately worse, slightly worse, no change, slightly improved, moderately improved, and markedly improved. The TSQ was rated on a 5-point scale, participant was asked: "overall how satisfied are you with your medication?": very satisfied, somewhat satisfied, neither dissatisfied nor satisfied, somewhat dissatisfied, and very dissatisfied.

\section{Inclusion and Exclusion Criteria}

Qualified researchers confirmed and documented inclusion criteria for each patient. Inclusion and exclusion criteria are shown in Supplementary material 1.

\section{Assessment}

The aim of this trial was to evaluate the efficacy and safety of naftopidil compared to tamsulosin in patients with neurogenic LUTD. The primary endpoint of efficacy was to compare the change of IPSS total score (excluding QoL) after 8 weeks of treatment versus baseline. A secondary endpoint of efficacy was based on changes in baseline values for the following tests: uroflowmetry with PVR, IPSS subdomain, and QoL score, urinary frequency and nocturia, BSW-Q, GRA-K, and TSQ. Safety endpoints consisted of treatment emergent adverse events (TEAEs), adverse drug reactions (ADRs), and serious AE/ADR. All adverse events were classified according to WHO Adverse Reaction Terminology (WHO-ART092).

\section{Statistical Methods}

The change in the 8-week IPSS total score versus baseline was projected to be approximately 8 to 9 in the 2 treatment groups and the standard deviation was projected to be approximately 7 . 
The noninferiority limit of naftopidil for tamsulosin was defined as 3, which was assumed to maintain about $60 \%-70 \%$ of the tamsulosin effect regarding the change in 8-week IPSS total score versus baseline. Under this assumption, the sample size for the evaluation of noninferiority at $80 \%$ power and $2.5 \%$ onesided significance level was 172 cases, i.e., 86 cases per treatment group. A total of 204 subjects were recruited with 102 cases per treatment group considering a 15\% dropout rate. For primary endpoint, to demonstrate noninferiority of naftopidil to tamsulosin, if the upper limit of 2-sided 95\% confidence interval (CI) for differences in least square means between 2 treatment groups (naftopidil-tamsulosin) calculated using an analysis of covariance (ANCOVA) model in which baseline values were used as a covariate was less than noninferiority margin of 3 points, then naftopidil was considered to be noninferior to tamsulosin. For efficacy assessment, an ANCOVA model with baseline values as a covariate was used to compare the endpoints between treatment groups for continuous data and the chi-square test or Fisher exact test was used for categorical data. For safety assessment, frequencies and percentages of subjects who experienced AEs were summarized and the difference of incidence rate between treatment groups was compared using the chisquare test or Fisher exact test. Statistical analysis was performed using the SAS ver. 9.2 (SAS Institute, Cary, NC, USA).

\section{RESULTS}

Baseline characteristics of the 194 subjects enrolled in this trial

Table 1. Baseline characteristics (intent-to-treat set)

\begin{tabular}{|c|c|c|c|}
\hline Characteristic & Tamsulosin $(\mathrm{n}=99)$ & Naftopidil $(n=95)$ & P-value \\
\hline Age (yr) & $59.07 \pm 10.77$ & $61.11 \pm 12.29$ & 0.097 \\
\hline Male sex & $37(37.37)$ & $35(36.84)$ & 0.939 \\
\hline Height $(\mathrm{cm})$ & $159.25 \pm 8.61$ & $159.44 \pm 8.41$ & 0.764 \\
\hline Weight (kg) & $60.64 \pm 9.35$ & $59.86 \pm 8.72$ & 0.552 \\
\hline $\begin{array}{l}\text { Urodynamic study } \\
\text { Qmax }(\mathrm{mL} / \mathrm{sec}) \\
\text { PdetQmax }\left(\mathrm{cm} \mathrm{H}_{2} \mathrm{O}\right) \\
\text { BOOI } \\
\text { BCI }\end{array}$ & $\begin{array}{l}10.35 \pm 5.07 \\
35.97 \pm 23.44 \\
15.87 \pm 24.36 \\
86.24 \pm 34.64\end{array}$ & $\begin{array}{l}10.90 \pm 8.15 \\
36.90 \pm 22.62 \\
15.03 \pm 30.87 \\
90.30 \pm 42.09\end{array}$ & $\begin{array}{l}0.913 \\
0.532 \\
0.760 \\
0.726\end{array}$ \\
\hline Lower urinary tract sympton & & & \\
\hline $\begin{array}{l}\text { Storage symptoms } \\
\text { Frequency } \\
\text { Nocturia } \\
\text { Urgency } \\
\text { Incontinence }\end{array}$ & $\begin{array}{l}96(96.97) \\
83 \\
86 \\
70 \\
30\end{array}$ & $\begin{array}{c}92(96.84) \\
83 \\
79 \\
75 \\
42\end{array}$ & 1.000 \\
\hline $\begin{array}{l}\text { Voiding symptoms } \\
\text { Weak stream } \\
\text { Splitting } \\
\text { Intermittency } \\
\text { Hesitancy } \\
\text { Straining } \\
\text { Terminal dribbling }\end{array}$ & $\begin{array}{c}97(97.98) \\
93 \\
35 \\
64 \\
49 \\
70 \\
32\end{array}$ & $\begin{array}{c}94(98.95) \\
89 \\
34 \\
59 \\
44 \\
62 \\
28\end{array}$ & 1.000 \\
\hline $\begin{array}{l}\text { Postmicturition symptoms } \\
\text { Dribbling } \\
\text { Incomplete emptying }\end{array}$ & $\begin{array}{l}93(93.94) \\
29 \\
87\end{array}$ & $\begin{array}{l}84(88.42) \\
26 \\
81\end{array}$ & 0.174 \\
\hline Others & $2(2.02)$ & $5(5.26)$ & 0.272 \\
\hline $\begin{array}{l}\text { Location of neurogenic cause } \\
\text { Brain } \\
\text { Spinal cord } \\
\text { Periphery } \\
\text { Others }\end{array}$ & $\begin{array}{l}21(21.21) \\
52(52.53) \\
24(24.24) \\
3(3.03)\end{array}$ & $\begin{array}{l}11(11.58) \\
54(56.84) \\
30(31.58) \\
1(1.05)\end{array}$ & $\begin{array}{l}0.071 \\
0.546 \\
0.254 \\
0.621\end{array}$ \\
\hline
\end{tabular}

Values are presented as mean \pm standard deviation or number (\%).

Qmax, maximum flow rate; PdetQmax, detrusor pressure at maximum flow rate; BOOI, bladder outlet obstruction index; BCI, bladder contractility index. 
are presented in Table 1. There were no differences between the 2 groups in pretreatment characteristics such as urodynamic study results, type of LUTS, and causes of neurogenic bladder. The medication compliance rate was $94.0 \%$ for the entire study group, $93.6 \%$ for the naftopidil group, and $94.4 \%$ for the tamsulosin group, for a total of 194 patients included in the intent-totreat set consisted of all randomized subjects.

Of the 194 randomized subjects ( 95 naftopidil and 99 tamsulosin), 181 (89 naftopidil and 92 tamsulosin) who received at least one dose of clinical trial medication and could be evaluated for the primary efficacy endpoint after randomization were included in the full-analysis (FA) set. The safety analysis group was defined as at least one dose of the clinical trial drug and one or more safety-related evaluations by telephone or visit after drug administration. Of the 194 randomly assigned subjects, 189 who received a clinical trial drug (92 naftopidil and 97 tamsulosin) were included in the safety analysis group, excluding 5 (3 naftopidil, 2 tamsulosin) (Fig. 1).
Both groups showed a statistically significant decrease in the FA set of IPSS total score at 8 weeks (mean change of the naftopidil group, $-5.64 \pm 0.66$; tamsulosin group, $-6.53 \pm 0.65$, respectively, $\mathrm{P}<0.0001$ ). The mean difference between both groups was 0.89 , and upper limit of $95 \%$ CI for the difference between the 2 groups was 2.72, which was lower than the noninferiority limit of 3 points. Therefore, compared with tamsulosin, naftopidil was found to be noninferior in IPSS total score change at 8 weeks (Table 2).

For secondary endpoints, all variables of uroflowmetry and PVR parameters (Table 3), IPSS subdomain and QoL score (Fig. 2), urinary frequency and nocturia (Fig. 3) at 4 and 8 weeks were not significantly different between the tamsulosin and naftopidil groups. There were also no differences between groups at 8 weeks in the BSW-Q, GRA-K, and TSQ. There were significant differences between the tamsulosin and naftopidil groups in the response distribution of the GRA-K $(\mathrm{P}=0.0318)$ and TSQ $(\mathrm{P}=$ $0.0095)$ at 4 weeks.

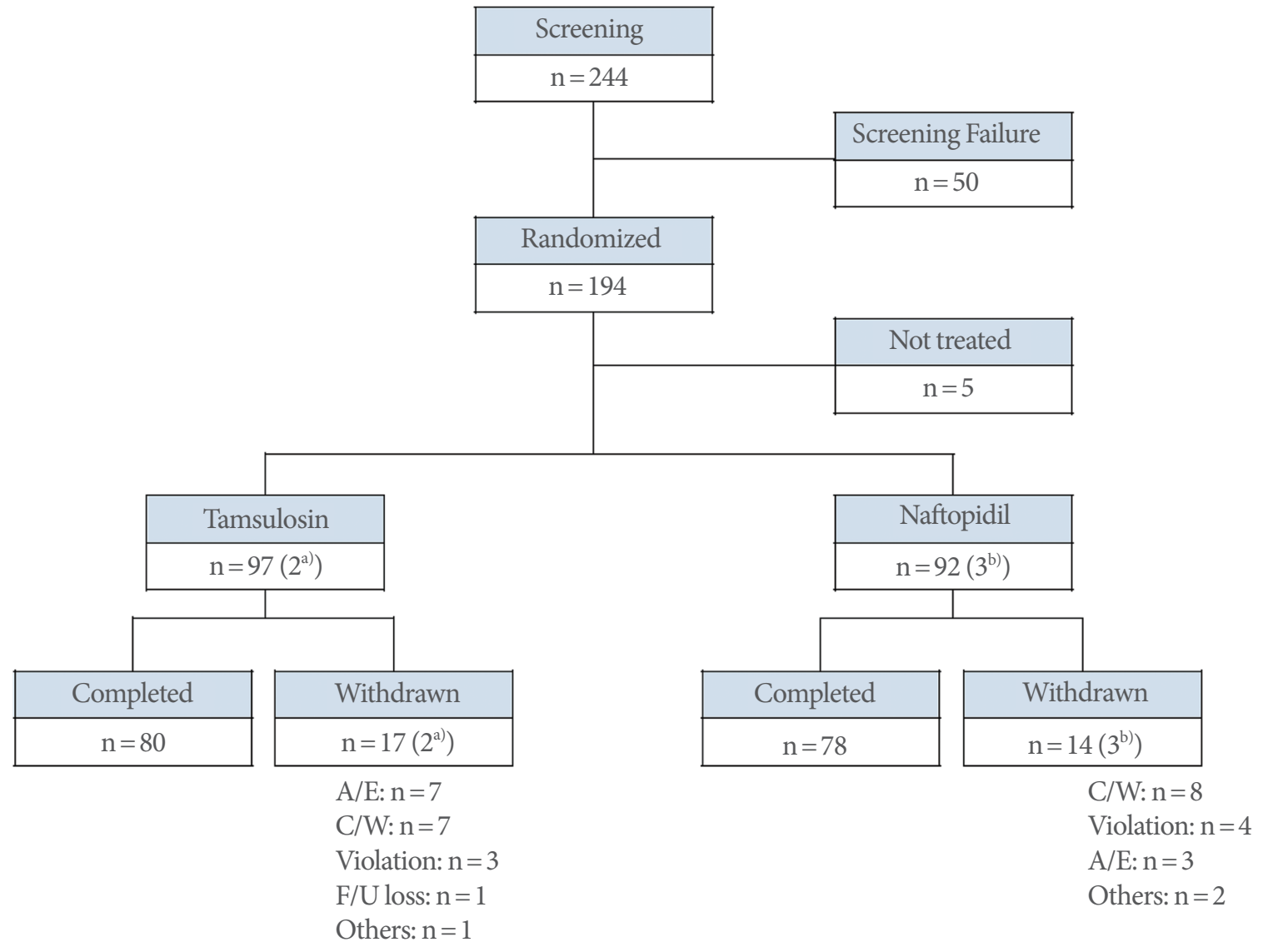

Fig. 1. Flow chart of the study. $A / E$, adverse events; $C / W$, consent withdrawal; $F / U$, follow-up. ${ }^{\text {a) }} \mathrm{C} / \mathrm{W}: \mathrm{n}=1$; Violation: $\mathrm{n}=1 .{ }^{\mathrm{b})} \mathrm{C} / \mathrm{W}$ : $\mathrm{n}=2$; Others: $\mathrm{n}=1$. 
Table 2. Change from baseline in IPSS total score (full analysis set)

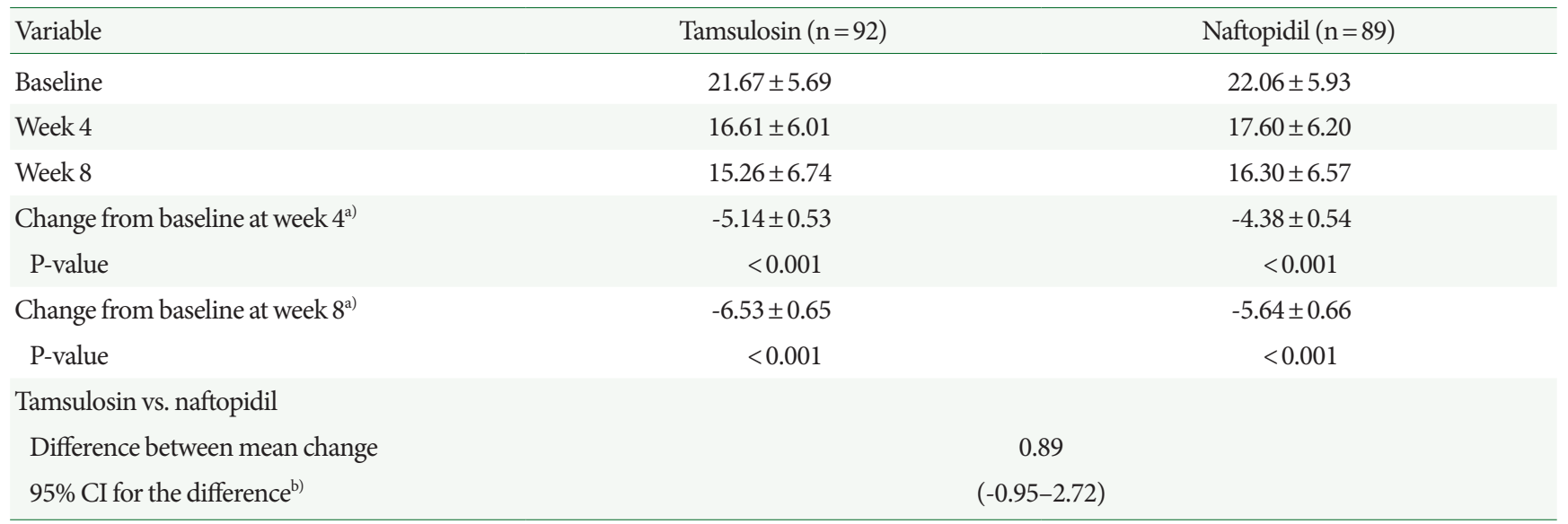

IPSS, International Prostatic Symptom Score; CI, confidence interval; ANCOVA, analysis of covariance.

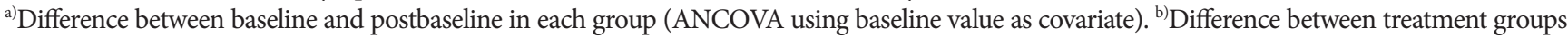
(ANCOVA using baseline value as covariate).

Table 3. Uroflowmetry and PVR evaluation between the tamsulosin and naftopidil groups

\begin{tabular}{|c|c|c|c|}
\hline Variable & Tamsulosin $(\mathrm{n}=92)$ & Naftopidil $(\mathrm{n}=89)$ & P-value \\
\hline \multicolumn{4}{|l|}{ Qmax } \\
\hline Change from baseline at week 4 & $3.18 \pm 0.74^{*}$ & $2.15 \pm 0.74^{*}$ & 0.326 \\
\hline Change from baseline at week 8 & $4.00 \pm 0.78^{*}$ & $3.22 \pm 0.79^{*}$ & 0.487 \\
\hline \multicolumn{4}{|l|}{ Qmean } \\
\hline Change from baseline at week 4 & $1.34 \pm 0.35^{*}$ & $0.40 \pm 0.35$ & 0.058 \\
\hline Change from baseline at week 8 & $1.55 \pm 0.34^{*}$ & $0.85 \pm 0.35^{*}$ & 0.146 \\
\hline \multicolumn{4}{|l|}{ PVR } \\
\hline Change from baseline at week 4 & $-21.46 \pm 5.47^{\star}$ & $-28.87 \pm 5.54^{\star}$ & 0.343 \\
\hline Change from baseline at week 8 & $-16.20 \pm 6.16^{*}$ & $-16.90 \pm 6.23^{\star}$ & 0.936 \\
\hline \multicolumn{4}{|l|}{ Voided volume } \\
\hline Change from baseline at week 4 & $5.47 \pm 14.82$ & $-24.28 \pm 14.82$ & 0.159 \\
\hline Change from baseline at week 8 & $2.90 \pm 13.98$ & $7.99 \pm 14.22$ & 0.799 \\
\hline \multicolumn{4}{|l|}{$\mathrm{PVR} /($ voided volume $+\mathrm{PVR}) \times 100 \%$} \\
\hline Change from baseline at week 4 & $-2.28 \pm 2.10$ & $-2.16 \pm 2.09$ & 0.968 \\
\hline Change from baseline at week 8 & $-4.21 \pm 1.67^{\star}$ & $-1.98 \pm 1.69$ & 0.350 \\
\hline
\end{tabular}

Values are presented as mean \pm standard error.

PVR, postvoid residual; Qmax, maximum flow rate; Qmean, mean flow rate; ANCOVA, analysis of covariance. ${ }^{\star} \mathrm{P}<0.05$, difference between baseline and postbaseline (ANCOVA using baseline value as covariate).

The subgroup analysis of neurologic lesions showed that there was no mean difference (naftopidil group - tamsulosin group) in IPSS total score change at 8 weeks between the 2 treatment groups. The mean difference of IPSS total score was -0.79 (95\% CI, -6.02 to 4.43$)$ in subjects with brain lesions, 0.63 $(-1.86$ to 3.13$)$ in subjects with spinal cord problems, and 2.51
(-1.16 to 6.17) in subjects with peripheral nervous disease. There was no difference between the 2 groups according to sex. The mean difference of the IPSS total score change at 8 weeks between the 2 treatment groups was -0.36 ( -3.52 to 2.81$)$ for male subjects and 1.51 ( -0.81 to 3.84$)$ for female subjects.

During the trial, 97 TEAEs occurred in 57 subjects (30.16\%) 

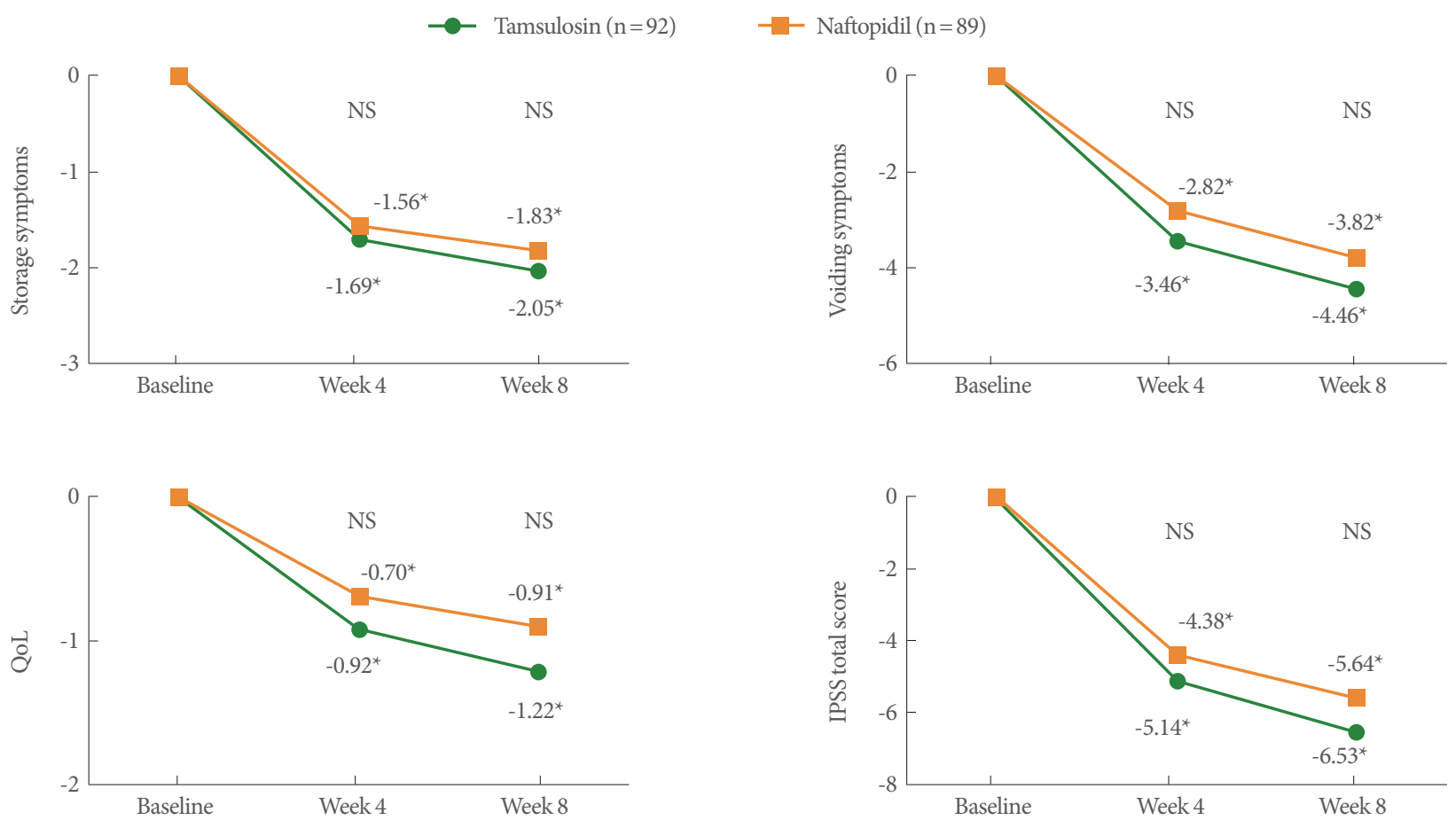

Fig. 2. Change from baseline to 4 and 8 weeks in International Prostatic Symptom Score (IPSS) and quality of life (QoL) score. ${ }^{\star}$ Statistically significant change from baseline. NS, statistically nonsignificant change between the tamsulosin and naftopidil group.
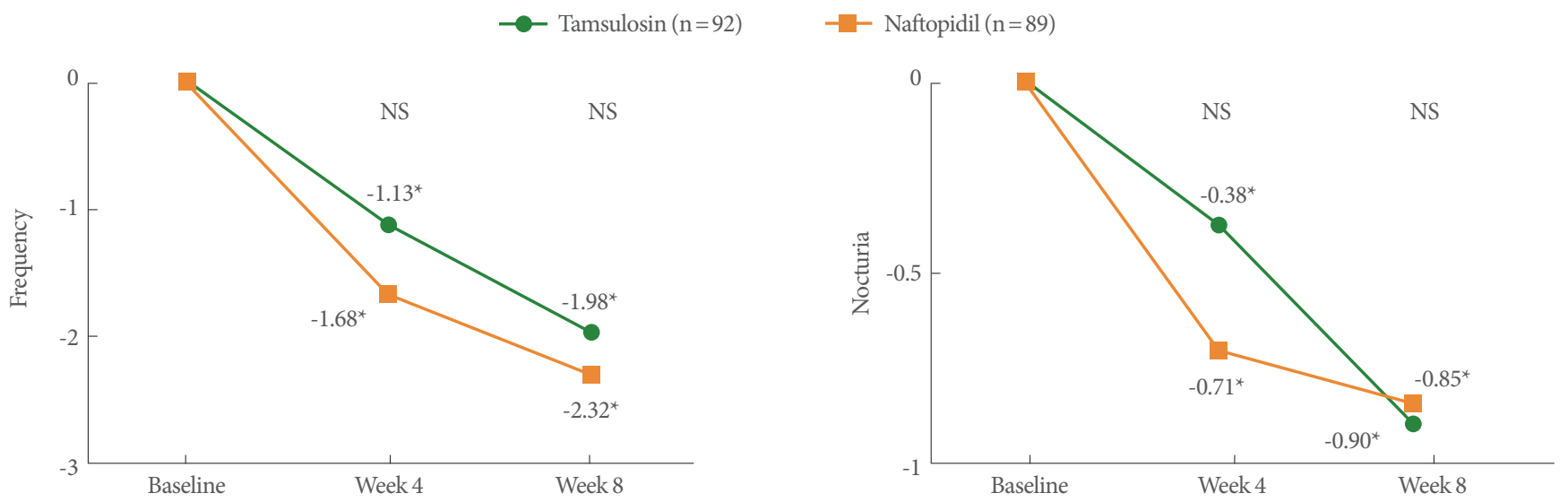

Fig. 3. Change from baseline to 4 and 8 weeks in urinary frequency and nocturia. ${ }^{\star}$ Statistically significant change from baseline. NS, statistically nonsignificant change between the tamsulosin and naftopidil group.

of the 189 subjects for safety analysis set, including 27 subjects (29.35\%, 42 cases) in the naftopidil group and 30 subjects (30.93\%, 55 cases) in the tamsulosin group, and there was no difference of incidence rate between the treatment groups $(\mathrm{P}=$ 0.8130). Eleven serious AEs occurred in 9 subjects (4.76\%), 2 with naftopidil (2.17\%, 4 cases), and 7 with tamsulosin $(7.22 \%$, 7 cases). There was no difference of incidence rate of serious AEs between the treatment groups $(P=0.1705)$. Five $A E s$ that resulted in temporary discontinuation of the medication occurred in 2 subjects (1.06\%), 1 in the naftopidil group (1.09\%, 2 cases), and 1 in the tamsulosin group (1.03\%, 3 cases). There was no difference of incidence rate of AEs which resulted in temporary discontinuation of the medication between the treatment groups $(\mathrm{P}=1.0000)$. Three patients $(3.26 \%, 6$ cases) in the naftopidil group and 7 patients $(7.22 \%, 10$ cases) in the tamsulosin group needed to discontinue medication perma- 
Table 4. Overall summary of adverse drug reactions during clinical trial

\begin{tabular}{|c|c|c|c|}
\hline Variable & Tamsulosin $(\mathrm{n}=97)$ & Naftopidil $(n=92)$ & P-value \\
\hline Subject with ADRs (cases) & $10(17)$ & $5(7)$ & 0.2153 \\
\hline \multicolumn{4}{|l|}{ Severity } \\
\hline Mild & 10 & 4 & \\
\hline Moderate & 7 & 3 & \\
\hline Severe & 0 & 0 & \\
\hline Subjects with serious ADRs & 0 & 0 & \\
\hline Subjects with ADRs Leading to temporarily discontinuation (cases) & $1(2)$ & 0 & 1.000 \\
\hline Subjects with ADRs leading to permanently discontinuation (cases) & $5(8)$ & $2(2)$ & 0.445 \\
\hline Subjects with ADRs leading to death & 0 & 0 & \\
\hline
\end{tabular}

ADRs, adverse drug reactions.

nently $(\mathrm{P}=0.3322)$. No AE-related death was reported during this trial. ADRs are shown in Table 4. Ten ADR cases that resulted in permanent discontinuation of the drug were reported in 7 patients, including dyspepsia $(\mathrm{n}=1)$ and nausea $(\mathrm{n}=1)$ in the naftopidil group, and urinary incontinence $(n=2)$, urinary frequency $(\mathrm{n}=1)$, abdominal pain $(\mathrm{n}=1)$, dizziness $(\mathrm{n}=1)$, tremor $(\mathrm{n}=1)$, pruritus $(\mathrm{n}=1)$, and skin rash $(\mathrm{n}=1)$ in the tamsulosin group. Of these, all of the ADRs that resulted in permanent discontinuation of naftopidil were mild or moderate, and all resolved without sequelae except urinary incontinence $(n=1)$, urinary frequency $(n=1)$ in the tamsulosin group. There were no AEs that resulted in serious ADRs or death in this trial, and no other specific finding was found in other safety profiles. Therefore, it was confirmed that the safety profile of naftopidil did not differ from that of tamsulosin.

\section{DISCUSSION}

The aim of this trial was to evaluate the efficacy and safety of naftopidil in patients with neurogenic LUTS. After 8 weeks of administration, both the naftopidil and tamsulosin groups showed statistically significant improvement in the primary efficacy variable of total IPSS, and naftopidil was not inferior to tamsulosin in terms of improved total IPSS. In addition, there was no significant difference between the tamsulosin and naftopidil groups in all variables at 4 and 8 weeks in uroflowmetry and PVR changes or questionnaires about urinary symptom changes. There were significant differences between the tamsulosin and naftopidil groups in the GRA-K $(\mathrm{P}=0.0318)$ and TSQ $(\mathrm{P}=0.0095)$ at 4 weeks. However, when the results were subdivided into 3 categories (improvement, no change, or deteriora- tion for the GRA-K, and satisfaction, no satisfaction and no dissatisfaction, or dissatisfaction for the TSQ), there was no difference between the groups even at 4 weeks.

Alpha-blockers may play an important role in improving emptying by decreasing outlet resistance in neurogenic LUTD. Alpha-blockers decrease PVR and increase urinary flow rate in patients with a neurogenic bladder [11,12]. Kakizaki et al. [11] reported that tamsulosin reduces functional urethral resistance during voiding and improves the flow rate in patients with a neurogenic bladder. Alpha-blockers have also been shown to decrease detrusor overactivity on urodynamic studies [13] and have beneficial effects on storage symptoms [14]. In patients with a neurogenic bladder and poor bladder compliance, combination medical therapy including $\alpha$-blockers significantly improves compliance, decreases bladder pressure at capacity and improves clinical outcomes compared to single antimuscarinic therapy $[15,16]$. Collectively, $\alpha$-blockers have some modest effects in patients with a neurogenic bladder in facilitation of voiding, but also serve to increase capacity and compliance in combination with anticholinergics [17]. In addition, $\alpha$-blockers have some effects on preventing serious harm from autonomic dysreflexia $[2,12,18]$. Krum et al. [19] reported that $\alpha$-blockers significantly decrease the magnitude of hypertension and severity of secondary symptoms during autonomic dysreflexia triggered by a variety of iatrogenic stimuli.

Although a-blockers have shown some clinical effects on neurogenic bladders, the precise mechanisms of action are still unknown. Abrams et al. [1] found that tamsulosin decreases maximum urethral pressure in patients with neurogenic LUTD. Bladder outlet obstruction can be reduced by a decrease in the maximum urethral pressure in patients with spinal cord injury 
(SCI) [20]. Regarding the expression of a1-ARs in the human spinal cord, a1AR mRNA is predominantly present in ventral gray matter (ventral $>$ dorsal; sacral $>$ lumbar $=$ thoracic $>$ cervic al), while a1D-AR is the predominant receptor subtype overall [21]. Traditionally, a1D-ARs are known to be mainly expressed in the bladder detrusor, with higher mRNA expression than that of a1A-Ars [22,23]. Thus, a1D-ARs are believed to be closely involved in storage symptoms. In a recent report using a decerebrated rat model with SCI, Ishida et al. [24] measured sphincter electromyography activity and demonstrated that naftopidil increased voiding efficiency by reducing external urethral sphincter resistance, while silodosin did not affect any parameters. The authors concluded that a1D-AR plays an important role in maintaining external urethral sphincter activity in the spinal cord, and a1D-blockade may influence the activity of Onuf's nuclei motor neurons, resulting in a decrease in external urethral sphincter tone.

Despite these data, the clinical effects of naftopidil on neurogenic LUTD have been rarely reported. A Japanese naftopidil neurogenic LUTD study group demonstrated that naftopidil has a significant effect on both symptoms and urodynamic variables of patients of both sexes with neurogenic LUTD [6]. They also found that PVR $<300 \mathrm{~mL}$ and bladder contractility are predictive factors for the efficacy of naftopidil. Theirs was the first report regarding the effect of naftopidil in neurogenic LUTD, although it was not a comparative study. In the current study, naftopidil improved subjective symptoms and objective findings in patients with neurogenic LUTD, and its effects were not inferior to those of tamsulosin. These results were effective regardless of sex or neurological causes. To our best knowledge, this is the first randomized controlled study to compare naftopidil and the other subtype of a1-blockers (e.g., tamsulosin) in neurogenic LUTD.

This study has several limitations. First, when managing neurogenic LUTD in real clinical practice, it is much more common to use a combination of medications including anticholinergics and $\beta 3$-agonist than $\alpha$-blockers alone. The trial treatment strategy may not fit well with actual clinical situations. Second, there was no evaluation of long-term outcomes, given the follow-up period of only 8 weeks. Although the follow-up period was short, it was considered sufficient to compare the effects and side effects of the 2 drugs.

In conclusion, this clinical trial demonstrated that naftopidil was not inferior to tamsulosin as a therapeutic drug for patients with neurogenic LUTD. Naftopidil had a safety profile similar to tamsulosin and should be considered as a safe drug that can improve symptoms in patients with neurogenic LUTD.

\section{SUPPLEMENTARY MATERIAL}

Supplementary material 1 can be found via https://doi.org/ 10.5213/inj.1938198.099.

\section{ACKNOWLEDGMENTS}

The following investigators also participated in the study:

Jong Bo Choi, Ajou University School of Medicine, Suwon; Hyeong-Gon Kim, Konkuk University Medical Center, Seoul; Jeong Gu Lee, Korea University College of Medicine, Seoul; SeungJune Oh, Seoul National University Hospital, Seoul; Seong Jin Jeong, Seoul National University Bundang Hospital, Seongnam; Ju Tae Seo, Cheil General Hospital \& Women's Healthcare Center, Seoul; Ha Na Yoon, Ewha Womans University, Seoul; SunOuck Kim, Chonnam National University Hospital, Gwangju; Khae Hawn Kim, Gachon University Gil Medical Center, Incheon; Jeong Zoo Lee, Pusan National University Hospital, Busan; Tae Yoong Jeong, Myongii Hospital, Goyang, Korea.

\section{AUTHOR CONTRIBUTION STATEMENT}

- Conceptualization: KSL

- Formal Analysis: HHS, KSL

- Investigation: HHS, MSC, JCK, JHK, KSL

- Methodology: MSC, JCK, JHK, KSL

- Project Administration: MSC, JCK, JHK, KSL

-Writing - Original Draft: HHS

- Writing - Review \& Editing: MSC, JCK, JHK, KSL

\section{REFERENCES}

1. Abrams P, Amarenco G, Bakke A, Buczyński A, Castro-Diaz D, Harrison S, et al. Tamsulosin: efficacy and safety in patients with neurogenic lower urinary tract dysfunction due to suprasacral spinal cord injury. J Urol 2003;170(4 Pt 1):1242-51.

2. Eldahan KC, Rabchevsky AG. Autonomic dysreflexia after spinal cord injury: systemic pathophysiology and methods of management. Auton Neurosci 2018;209:59-70.

3. Schwinn DA, Roehrborn CG. Alpha1-adrenoceptor subtypes and lower urinary tract symptoms. Int $J$ Urol 2008;15:193-9.

4. Gu BJ, Ishizuka O, Igawa Y, Nishizawa O, Andersson KE. Role of 
supraspinal alpha1-adrenoceptors for voiding in conscious rats with and without bladder outlet obstruction. J Urol 2002;167:188791.

5. Kim DK, Lee JY, Jung JH, Kim JH, Hah YS, Hong CH, et al. Alpha-1 adrenergic receptor blockers for the treatment of lower urinary tract symptoms in women: a systematic review and metaanalysis. Int Neurourol J 2019;23:56-68.

6. Takeda M, Homma Y, Araki I, Kakizaki H, Yamanishi T, Yokota T, et al. Predictive factors for the effect of the al-D/A adrenoceptor antagonist naftopidil on subjective and objective criteria in patients with neurogenic lower urinary tract dysfunction. BJU Int 2011;108:100-7.

7. Shibata K, Foglar R, Horie K, Obika K, Sakamoto A, Ogawa S, et al. KMD-3213, a novel, potent, alpha 1a-adrenoceptor-selective antagonist: characterization using recombinant human alpha 1-adrenoceptors and native tissues. Mol Pharmacol 1995;48:250-8.

8. Takei R, Ikegaki I, Shibata K, Tsujimoto G, Asano T. Naftopidil, a novel alpha1-adrenoceptor antagonist, displays selective inhibition of canine prostatic pressure and high affinity binding to cloned human alpha1-adrenoceptors. Jpn J Pharmacol 1999;79:447-54.

9. Hwang EC, Gandhi S, Jung JH, Imamura M, Kim MH, Pang R, et al. Naftopidil for the treatment of lower urinary tract symptoms compatible with benign prostatic hyperplasia. Cochrane Database Syst Rev 2018;10:CD007360.

10. Cho SY, Lee HE, Jeong SJ, Oh SJ. Translation and linguistic validation of the Korean version of the "benefit, satisfaction, and willingness to continue" questionnaire for patients with overactive bladder. Int Neurourol J 2016;20:255-9.

11. Kakizaki H, Ameda K, Kobayashi S, Tanaka H, Shibata T, Koyanagi T. Urodynamic effects of alpha1-blocker tamsulosin on voiding dysfunction in patients with neurogenic bladder. Int J Urol 2003;10:57681.

12. Chancellor MB, Erhard MJ, Hirsch IH, Stass WE Jr. Prospective evaluation of terazosin for the treatment of autonomic dysreflexia. J Urol 1994;151:111-3.

13. Ueda S, Satake N, Shibata S. Alpha 1- and alpha 2-adrenoceptors in the smooth muscle of isolated rabbit urinary bladder and urethra. Eur J Pharmacol 1984;103:249-54.

14. Andersson K. alpha1-adrenoceptors and bladder function. Eur
Urol 1999;36 Suppl 1:96-102.

15. Cameron AP, Clemens JQ, Latini JM, McGuire EJ. Combination drug therapy improves compliance of the neurogenic bladder. J Urol 2009;182:1062-7.

16. Wada N, Shimizu T, Takai S, Shimizu N, Tyagi P, Kakizaki H, et al. Combinational effects of muscarinic receptor inhibition and $\beta 3$ adrenoceptor stimulation on neurogenic bladder dysfunction in rats with spinal cord injury. Neurourol Urodyn 2017;36:1039-45.

17. Romo PGB, Smith CP, Cox A, Averbeck MA, Dowling C, Beckford $C$, et al. Non-surgical urologic management of neurogenic bladder after spinal cord injury. World J Urol 2018;36:1555-68.

18. Phillips AA, Elliott SL, Zheng MM, Krassioukov AV. Selective alpha adrenergic antagonist reduces severity of transient hypertension during sexual stimulation after spinal cord injury. J Neurotrauma 2015;32:392-6.

19. Krum H, Louis WJ, Brown DJ, Howes LG. A study of the alpha-1 adrenoceptor blocker prazosin in the prophylactic management of autonomic dysreflexia in high spinal cord injury patients. Clin $\mathrm{Au}-$ ton Res 1992;2:83-8.

20. Bennett JK, Foote J, El-Leithy TR, Saleem MD, Green B, Archer $\mathrm{CL}$, et al. Terazosin for vesicosphincter dyssynergia in spinal cordinjured male patients. Mol Urol 2000;4:415-20.

21. Smith MS, Schambra UB, Wilson KH, Page SO, Schwinn DA. Alpha1-adrenergic receptors in human spinal cord: specific localized expression of mRNA encoding alpha1-adrenergic receptor subtypes at four distinct levels. Brain Res Mol Brain Res 1999;63:25461.

22. Hampel C, Dolber PC, Smith MP, Savic SL, Th roff JW, Thor KB, et al. Modulation of bladder alpha1-adrenergic receptor subtype expression by bladder outlet obstruction. J Urol 2002;167:1513-21.

23. Malloy BJ, Price DT, Price RR, Bienstock AM, Dole MK, Funk BL, et al. Alpha1-adrenergic receptor subtypes in human detrusor. J Urol 1998;160(3 Pt 1):937-43.

24. Ishida $\mathrm{H}$, Yamauchi $\mathrm{H}$, Ito $\mathrm{H}$, Akino $\mathrm{H}$, Yokoyama O. a1DAdrenoceptor blockade increases voiding efficiency by improving external urethral sphincter activity in rats with spinal cord injury. Am J Physiol Regul Integr Comp Physiol 2016;311:R971-8. 